\section{A simple, inexpensive gel filtration technique for use in diagnostic serology}

\author{
J. R. PATTISON ${ }^{1}$ AND JENNIFER E. MACE From the \\ Department of Virology, The School of Pathology, \\ The Middlesex Hospital Medical School, London
}

Previously described methods (Best, Banatvala, and Watson, 1969; Gupta, Peterson, Stout, and Murphy, 1971; Haire and Hadden, 1972) for the separation of IgM and IgG as applied in diagnostic serology all involve at least moderate capital expenditure and/or a skilled, highly standardized technique. In investigating gel filtration techniques in order to define a simple, inexpensive, robust technique for the fractionation of human sera the following system has been devised. The basic technique has been applied in this laboratory for the past five years in the serological diagnosis of recent rubella and no difficulties in interpretation of the results have been encountered.

\section{Methods}

\section{A P PARATUS}

The cheapest automatic fraction collector available is the Boulting fraction collector (James A. Jobling, Laboratory Division, Stone, Staffs). The remainder of the system has been designed around this fraction collector so as to achieve the desired separation of IgM and IgG when collecting 4-5 $\mathrm{ml}$ fractions. The most convenient column for this has been found to be the $500 \times 20 \mathrm{~mm}$ Quickfit chromatographic column (Baird and Tatlock, Romford, Essex) packed to a length of 50 to $52 \mathrm{~cm}$ with Sephadex G-200 (Pharmacia, Uppsala, Sweden) suspended in

${ }^{1}$ Requests for reprints should be addressed to J. R. Pattison from whom more detailed instructions are available for those not familiar with gel filtration techniques.

Received for publication 10 January 1973.

A screening test for $\operatorname{Ig} G$ deficiency-continued.

Guthrie, R., and Susi, A. (1963). A simple phenylalamine method for detecting phenylketonuria in large populations of newborn infants. Pediatrics, 32, 338-343.

Medical Research Council (1971). Hypogammaglobulinaemia in the United Kingdom. Spec. Rep. Ser. med. Res. Coun. (Lond.), 310.

Newman, R. L., and Starr, D. J. T. (1971). Technology of a regional Guthrie test service. J. clin. Path., 24, 564-575.
Nairn PBS (Nairn, 1964) plus $0.02 \%$ sodium azide (PBS-NA). The remainder of the apparatus consists of a constant level solvent reservoir with an airtight feed to the top of the column. As illustrated this consists of a transfusion bottle, an intravenous infusion set with the filter removed, and a serum needle passing through a rubber bung (fig 1).

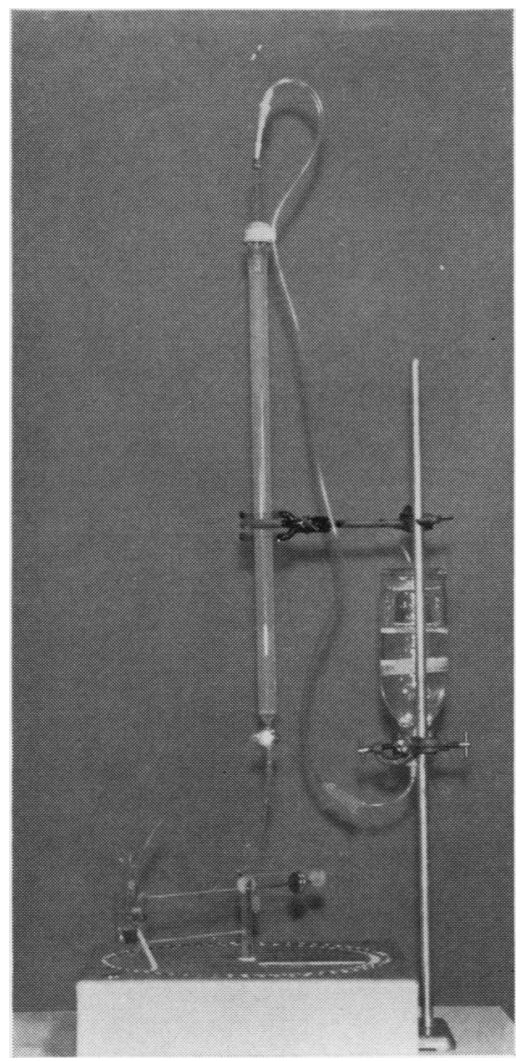

Fig. 1 The apparatus.

\section{FRACTIONATION OF SERA}

The technique is illustrated by its application to the serological diagnosis of recent rubella. Taking care not to disturb the gel itself, layer onto the top surface of the gel a sample (determined as one tenth the fraction volume, ie, $0.4-0.5 \mathrm{ml}$ ) of serum pretreated with $\mathrm{MnCl}_{2} /$ heparin $/ 50 \%$ pigeon $\mathrm{RBCs}$ (Dold and Northrop, 1968). Elute the serum sample at a rate of not more than $20 \mathrm{ml} / \mathrm{hr}$. After 40 fractions have been collected the column is cleared for the next run, and with such a system a single column will perform 30-50 fractionations. Rubella haemagglutination inhibition (HAI) tests are performed on the appropriate fractions (for methods of selec- 
tion of these see results section) from a dilution of 1 in 1 to 1 in 64 with a control lacking antigen for each fraction. A microtitre system was used involving the mixture of 4HA Units with serial doubling dilution of the eluted fractions using $0.4 \%$ bovalbumin-borate saline (Clarke and Casals, 1958) as both antigen and fraction diluent. Virus/fraction mixtures were incubated overnight before the addition of $0.25 \%$ pigeon RBCs (diluted in bovalbumin-DGV, Stewart, Parkman, Hopps, Douglas, Hamilton, and Meyer, 1967) as indicator.

\section{Results}

The system has been designed so that by titrating the appropriate 12 fractions the entire distribution of immunoglobulins will be covered (fig 2). These 12 fractions are most easily found as follows. Locate the first fraction which after vigorous shaking carries a persistent head of froth (in practice this should be fraction $7,8,9$, or 10 ). Choose two fractions before this as the first fraction for rubella HAI titration and titrate this and the subsequent 11 fractions across a microtitre plate.

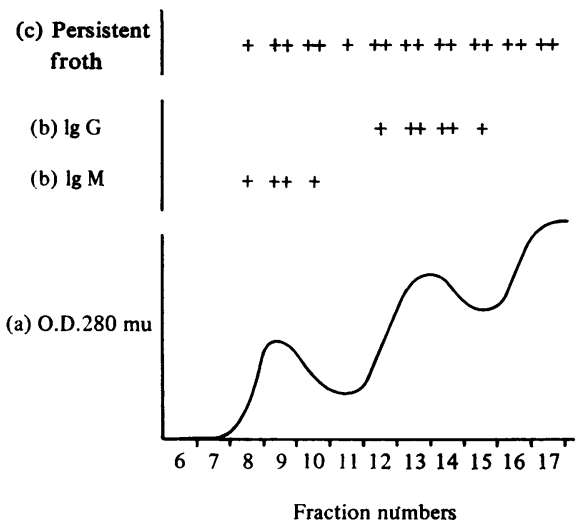

Fig. 2 Elution patterns of protein. Five ml fractions were eluted from a column of Sephadex G-200 as described and protein content measured as follows:

(a) continuous monitoring $O D 280 \mathrm{m \mu}$ with Uvicord II (LKB Instruments Ltd)

(b) measured, after concentration, in Immunoplates (Hyland Laboratories Inc)

(c) Froth persisting at 10 sec after vigorous shaking for three to four seconds.

Figure 3 illustrates the various patterns of rubella HAI activity that may be found with a particular column when collecting $5 \mathrm{ml}$ samples. Figure $3 \mathrm{~A}$ shows the result of fractionating a high titre serum in which all the rubella HAI activity is in the IgG class. As is typical, the HAI activity is distributed symmetrically over not more than eight fractions around a peak in fraction 13 or 14. Moreover no rubella HAI activity is found in the first two protein-

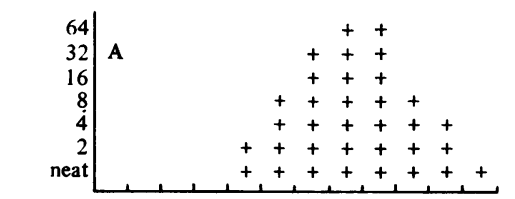

Straight Recovery

titre

$5120 \quad 4000$
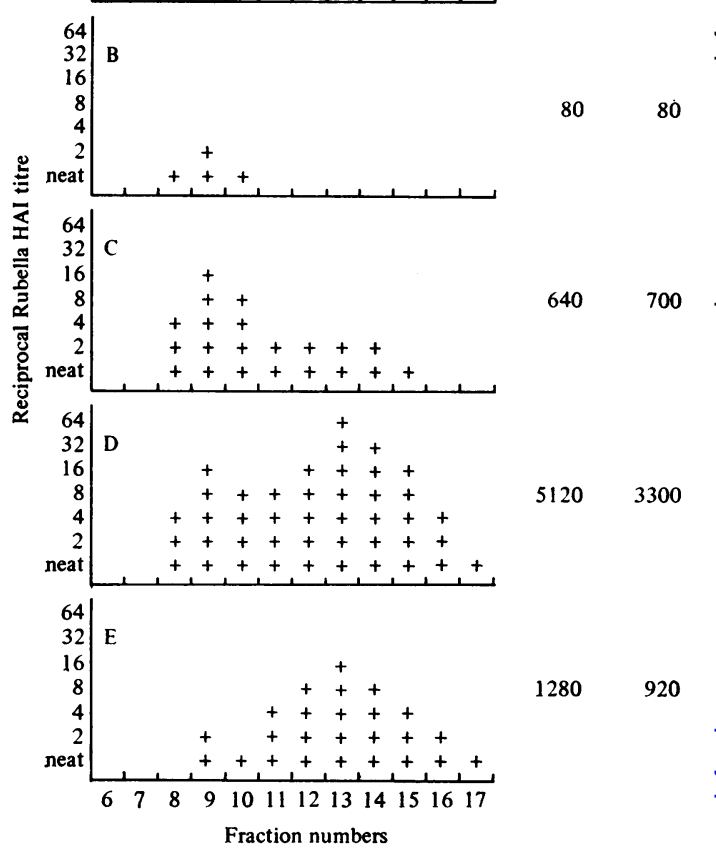

1280

920

Fig. 3 Patterns of rubella HAI activity in fractionated sera. Five ml fractions were eluted from the same columns used to acquire the data in figure 2. For further explanation see text.

containing fractions. Activity occurring in these early fractions, being IgM, is only found in sera $\sigma$ taken after recent rubella. The relative proportions of IgM and IgG activity in early convalescent sera is shown in fig 3 for sera taken two to three days (fig 3B), four to six days (fig 3C), 10-14 days (fig 3D), and four to six weeks (fig 3E) after the onset of the rubella rash. All these sera are from patients in whom rubella was diagnosed on the basis of rising titres.

An internal control of each fractionation is achieved by comparing the HAI activity appearing in the fractions (column recovery) with the reciprocal titre of the serum before gel filtration (straight titre). There should be less than one doubling dilution 
difference between the two. Fractions are diluted 1 in 20 by comparison with the original serum therefore the column recovery is obtained by adding together the reciprocal titres of all the fractions and multiplying by 20 .

\section{Comment}

The method is as inexpensive as possible granted that an automatic fraction collector is used. The total capital cost, assuming that one is already performing HAI tests is $\mathbf{f 5 0}$. The technique has been made as simple as possible by removing all strictly unnecessary steps. Accordingly interpretation of results has been based on an appreciation of the overall pattern of HAI activity within the IgM and IgG fractions so that no undue emphasis is placed one any one titration. Of course better separation can be achieved by using longer columns of gel but this inevitably increases the cost and technical difficulties.

Just as variations in any of the parameters of rubella HAI tests have been shown to alter the results obtained (Schmidt and Lennette, 1970), so do any changes in the method of fractionation of sera. It is emphasized that each of these variables has been investigated and that the detailed procedures described have been selected so that the method remains simple but gives accurate results without difficulties of interpretation. Although the use of the method has been illustrated only for rubella serology, it could be applied to any serological test which will accept an initial serum dilution of 1 in 20 and is not affected by the presence of Nairn PBS plus $0.02 \%$ sodium azide.

\section{References}

Beest, J. M., Banatvala, J. E., and Watson, D. (1969). Serum IgM and IgG responses in postnatally acquired rubella. Lancet, 2, 65-68.

Clarke, D. H., and Casals, J. (1958). Techniques for hemagglutination and hemagglutination-inhibition with arthropod-borne viruses. Amer. J. Trop. Med. Hyg., 7, 561-573.

Dold, H. J., and Northrop, R. L. (1968). The non-specific inhibitors of rubella-virus hemagglutination. Proc. Soc. exp. Biol. (N.Y.), 128, 577-581.

Gupta, J. D., Peterson, V., Stout, M., and Murphy, A. M. (1971). Single-sample diagnosis of recent rubella by fractionation of antibody on Sephadex G-200 column. J. clin. Path., 24, 547-550.

Haire, M., and Hadden, D. S. M. (1972). Rapid diagnosis of rubella by demonstrating rubella specific IgM antibodies in the serum by indirect immunofluorescence. J. med. Microbiol., 5, 237-242.

Nairn, R. C. (1964). Fluorescent Protein Tracing, 2nd ed. Livingstone, Edinburgh and London.

Schmidt, N. J., and Lennette, E. H. (1970). Variables of the rubellahemagglutination inhibition test system and their effect on antigen and antibody titres. Appl. Microbiol., 19, 491-504.

Stewart, G. L., Parkman, P. D., Hopps, H. E., Douglas, R. D., Hamilton, J. P., and Meyer, H. M., Jnr. (1967). Rubella-virus hemagglutination inhibition test. New Engl. J. Med., 276, 554-557.

\section{Wet ashing using a closed system}

GEORGE P. LEWIS AND LINDA L. COUGHLIN From the Section of Clinical Pharmacology, Boston Veterans Administration Hospital and Tufts University School of Medicine, Boston, Massachusetts

Wet ashing procedures are being used more extensively because of the increased interest in the biological role of trace metals. The standard procedures, using fuming nitric acid, or mixtures of concentrated acids are normally carried out within a laboratory hood, the acid fumes being vented through the hood's exhaust duct. To obtain adequate digestion, such techniques require the addition of several aliquots of acid. When large numbers of samples are being prepared, a considerable quantity of acid can be used in one day. These 'open' standard procedures lead to the emission of highly acid fumes into the ambient atmosphere, result in marked erosion of the hood's exhaust system, and can give rise to unacceptable levels of acid fume in the laboratory air. In order to overcome these objections, a 'closed' wet ashing system has been used in this laboratory during the past two years for the preparation of cadaver tissue samples for atomic absorption spectrophotometry (Lewis, Jusko, Coughlin, and Hartz, 1972a and b).

\section{Method}

Samples (kidneys $0 \cdot 5 \mathrm{~g}$, liver $2 \mathrm{~g}$, lungs $4 \mathrm{~g}$ ) are each placed in a $100 \mathrm{ml}$ Erlenmeyer flask. Each flask is fitted to a Stark-Dean distilling trap of $10 \mathrm{ml}$ capacity. Above the receiver is fitted a water-cooled condenser. All components have ground glass joints. The whole is then placed over a hot plate sited within a laboratory hood. Initially, the hot plate is set at $250^{\circ} \mathrm{C}$, and the acid and sample are allowed to simmer gently for two hours with the hood exhaust fan on. The circulation of air around the Erlenmeyer flask prevents distillation of the acid into the trap. After this time, when the tissue has been completely solubilized and digested, the hood fan is turned off, and the hot plate is turned up to $350^{\circ} \mathrm{C}$. The acid then refluxes into the trap over 20 to 30 minutes. When the volume of digest is reduced to 0.5 to $1.0 \mathrm{ml}$, heating is stopped by placing an asbestos pad between the hot plate and the Erlenmeyer flask. Following cooling, $15 \mathrm{ml}$ of distilled water is added to the digest, and the $\mathrm{pH}$ adjusted by titration to 3.5 with concentrated ammonium

Received for publication 1 December 1972. 